\title{
МОДЕЛЮВАННЯ НЕЙРОННОЇ МЕРЕЖІ ДЛЯ ВИЗНАЧЕННЯ СТАДІЇ ХВОРОБИ АЛЬЦГЕЙМЕРА
}

Проніна О. І., Яблокова А. В. Моделювання нейронної мережі для визначення стадї̈ хвороби Альизгеймера. Хвороба Альичгеймера є найбільш поширеним типом демениії в стані якої головний мозок людини перестає виконувати свої функиії належним чином. Дане захворювання викликає проблеми із пам'яттю, мисленням та поведінкою. Найбільш уразливими для изього захворювання є люди похилого віку та значну роль відіграє спадковість - якщо з'ясується, щзо в родині були випадки з таким захворюванням, то ризик захворіти є дуже високим. В останній час із проривним розвитком та впровадженням інформачійних технологій та методів машинного навчання як взагалі так особливо $і$ в медицині набуває популярності рання комп'ютерна діагностика хвороби, що використовує штучний інтелект, а саме - нейронні мережі. Основним завданням діагностування хвороби є правильне визначення стадії захворювання, спираючись на отримані знімки головного мозку, які видає пристрій магнітно-резонансної томографії після обстеження хворого, враховуючи його попередній анамнез та скарги. У даній роботі розглядається модель нейронної мережі для дослідження стадій хвороби Альигеймера. Розглянуто роль ранньої діагностики захворювання за допомогою штучного інтелекту, зокрема нейронними мережами. Були розглянуті основні методи, які застосовувались в дослідженнях для класифікаиії хвороби. На підставі аналізу літературних джерел була обрана згорткова архітектура нейронних мереж, яка показала більшу точність розпізнавання серед інших архітектур. Була розроблена математична модель згорткової нейронної мережі: обрано кількість згорткових, повнозв'язних шарів, кількість фільтрів у кожному шарі, функиї активащії для кожного шару, також було виконано налаштування гіперпараметрів для підвищення якості розпізнавання хвороби Альизеймера. Розроблена математична модель буде фундаментом для застосунка, щзо полегшить роботу лікаря для оцінки стадії захворювання Альизгеймера, дозволить робити більш точні діагнози, зменшить певне навантаження при виконанні рутинних дій медичного працівника. Використання циієї математичної моделі в комбінації із розробленим програмним забезпеченням дозволить прискорити встановлення остаточного діагнозу хворого.

Ключові слова: розпізнавання, класифікація, згорткова нейронна мережа, деменція, хвороба Альизеймера, архітектура нейронної мережі.

О.И. ПРОНИНА

ГВУЗ «Приазовский государственный технический университет» ORCID: 0000-0001-7085-8027

А.В. ЯБЛОКОВА

ГВУЗ «Приазовский государственный технический университет» ORCID: 0000-0002-4322-9994

\section{МОДЕЛИРОВАНИЕ НЕЙРОННОЙ СЕТИ ДЛЯ ОПРЕДЕЛЕНИЯ СТАДИИ БОЛЕЗНИ АЛЬЦГЕЙМЕРА}

Пронина О. И., Яблокова А. В. Моделирование нейронной сети для определения стадии болезни Альичгеймера. Болезнь Альизгеймера является наиболее распространенным типом демениии, в состоянии которой, головной мозг человека перестает выполнять свои функции должным образом. Данное заболевание вызывает проблемы с памятью, мышлением и поведением. Наиболее уязвимыли для этого заболевания являются пожилье люди и значительную роль играет наследственность - если выяснится, что в семье были случаи с таким заболеванием, то риск заболеть является очень высоким. В последнее время с прорывным развитием и внедрением информационных технологий и методов машинного обучения как вообще, так и особенно в медичине набирает популярность ранняя компьютерная диагностика болезни, которая использует искусственный интеллект, а именно - нейронные сети. Основной задачей диагностирования болезни является правильное определение стадии заболевания, опираясь на полученные снимки головного мозга, которые выдает устройство магнитно-резонансной томографии после обследования больного, учитывая его предыдущฺий анамнез и жалобы. В данной 
работе рассматривается модель нейронной сети для исследования стадий болезни Альцгеймера. Рассмотрена роль ранней диагностики заболевания с помощьью искусственного интеллекта, в частности нейронныли сетями. Были рассмотрены основные методы, которые применялись 6 исследованиях для классификации болезни. На основании анализа литературных источников была выбрана свёрточная архитектура нейронной сети, которая показала большую точность распознавания среди других архитектур. Была разработана математическая модель сверточной нейронной сети: выбрано количество сверточных, полносвязных слоев, количество фильтров в каждом слое, функиии активации для каждого слоя, также была выполнена настройка гиперпараметров для повышения качества распознавания болезни Альизгеймера. Разработанная математическая модель будет фундаментом для приложения, что облегчит работу врача для оценки стадии заболевания Альцฺгейера, позволит делать более точные диагнозы, уменьшит определенную нагрузку при выполнении рутинных действий медицинского работника. Использование этой математической модели в комбинации с разработанным программным обеспечением позволит ускорить установление окончательного диагноза больного.

Ключевые слова: распознавание, классификация, свёрточная нейронная сеть, деменция, болезнь Альизеймера, архитектура нейронной сети.

O.I. PRONINA

SHEI "Priazovsky State Technical University" ORCID: 0000-0001-7085-8027

A.V. YABLOKOVA

SHEI "Priazovsky State Technical University" ORCID: 0000-0002-4322-9994

\section{NEURAL NETWORK MODELING TO DETERMINE THE STAGE OF ALZHEIMER'S DISEASE}

Pronina O. I., Yablokova A. V. Neural network modelling to determine the stage of Alzheimer's disease. Alzheimer's disease is the most common type of dementia, in which the human brain ceases to perform its functions properly. This disease causes problems with memory, thinking and behavior. The elderly are the most vulnerable to this disease and heredity plays a significant role - if it turns out that there have been cases of such a disease in the family, then the risk of getting sick is very high. Recently, with the breakthrough development and introduction of information technologies and machine learning methods, both in general and especially in medicine, early computer diagnostics of the disease, which uses artificial intelligence, namely neural networks, is gaining popularity. The main task of diagnosing the disease is to correctly determine the stage of the disease, based on the obtained brain images, which are issued by the magnetic resonance imaging device after examination of the patient, taking into account his previous anamnesis and complaints. In this paper, we consider a neural network model for studying the stages of Alzheimer's disease. The role of early diagnosis of the disease with the help of artificial intelligence, in particular neural networks, is considered. The main methods that were used in research to classify the disease were considered. Based on the analysis of literature sources, a convolutional neural network architecture was chosen, which showed greater recognition accuracy among other architectures. A mathematical model of a convolutional neural network was developed: the number of convolutional, fully connected layers, the number of filters in each layer, activation functions for each layer were selected, hyperparameters were also configured to improve the quality of recognition of Alzheimer's disease. The developed mathematical model will be the foundation for the application, which will facilitate the work of a doctor to assess the stage of Alzheimer's disease, will make it possible to make more accurate diagnoses, will reduce a certain burden when performing routine actions of a medical worker. The use of this mathematical model in combination with the developed software will speed up the establishment of the final diagnosis of the patient.

Keywords: recognition, classification, convolutional neural network, dementia, Alzheimer's disease, neural network architecture.

\section{Постановка проблеми}

Рання діагностика хвороби - найважливіше завдання сучасної медицини. Чим раніше буде діагностовано захворювання, тим швидше можна буде запобігти розповсюдженню, ускладнення хвороби, простіше іiі вилікувати та набагато легше позбавитись від іiі наслідків. Оскільки кожний людський організм реагує по-різному на одне і теж саме захворювання, рання діагностика і виявлення прогресування захворювання мають вирішальне значення для запобігання фатальних помилок, тому це буде актуально у будь-які часи.

В медицині існує багато інструментів, за допомогою яких виконується виявлення захворювань. В останній час медицина переживає значній ріст впровадження машинного навчання, існує безліч додатків для нього та штучного інтелекту. Методи машинного навчання знайшли в медицині великий 
успіх: від прогнозування результатів лікування пацієнтів, закінчуючи підтримкою прийняття клінічних рішень та прогнозуванням майбутніх терапевтичних заданих значень пацієнта.

На жаль, існують такі захворювання, які важко діагностувати звичайними методами на ранній стадії. Тут на допомогу лікарю приходять методи машинного навчання: розпізнавання рентгенівського знімку грудної клітини про наявність чи відсутність захворювання, що уражує легені, а саме: Covid-19, прогнозування імовірності діагнозу глаукоми, прогнозування ризику серцевих захворювань, що в даний час $є$ одною із найчастіших причин смерті в даний час у всьому світі.

Одним 3 таких серйозних захворювань, де раннє діагностування відіграє важливу роль $є$ захворювання Альцгеймера [1]. Ця хвороба характеризується нейродегенеративним характером, що проявляється у когнітивних порушеннях, які стають помітними у середньому та частіше у похилому віку.

Аналіз останніх досліджень та публікацій

На сьогоднішній день існує багато робіт, що присвячені дослідженню хвороби Альцгеймера. Таким чином, в роботі [2] розглядається метод машинного навчання, що дозволяє діагностувати захворювання на основі спонтанного мовлення. Він представляє в своїй роботі нещодавно розроблений метод активного представлення даних ADR для обробки голосу як основа для об'єднання акустичних i текстових функцій на рівні речення та слова. В роботі використовувались комбінації між декількома конфігураціями функцій ADR і більш традиційними підходами з набором записів були використані в ансамблі з класифікаторами, побудованих і оцінених на стандартизованому наборі даних, що містять записану мову, описи сцен і текстові розшифровки. Результатом цієї роботи $є$ досягнута точність $89,85 \%$ i це лише використання семантичних характеристик.

В свою чергу, в роботі [3] розглянуто не тільки один метод машинного навчання для дослідження цієї хвороби. Ними проведено дослідження: в лікарні буди відібрані 18 пацієнтів 3 хворобою Альцгеймера та 18 пацієнтів без хвороби в якості експериментальної групи і зроблені МРТскани головного мозку. Після цього отримані зображення сегментувались різними алгоритмами: згортковою нейронною мережею (CNN), повною згортковою мережею (FCNN), методом опорних векторів (SVM). Вони дослідили, що модель згорткової нейронної мережі краще за всіх справилась із задачею сегментації зображень головного мозку.

Але, в роботі [4] також розглядається не один метод дослідження: розглянута комбінація методів машинного навчання: глибоке навчання використовується разом із методом дерев рішень. Автори стверджують, що таким чином, використовуючи в парі ці два методи - посилюється здатність поглинати характеристики із багатомірних даних і спрощується класифікація хвороби Альцгеймера.

Інша робота [5], що підкреслює важливість ранньої діагностики захворювання Альцгеймера, розглядає 4 методи машинного навчання: штучні нейронні мережі, логістична регресія, кластеризація за допомогою метода найближчого сусіда $(\mathrm{KNN})$ і дерева рішень. За допомогою перерахованих методів він виконував прогнозування значення клінічної оцінки деменції.

В роботі [6] розглянуто метод діагностики та прогнозування хвороби Альцгеймера шляхом обробки структурного магнітно-резонансного зображення (МРТ) за допомогою нейронних мереж глибокого навчання. Автор використав одну модель мереж глибокого навчання, яка є згортковою нейронною мережею. Він використовує чотири різні архітектури згорткових нейронних мереж, а саме архітектурy Lenet-5, AlexNet, ZFNet та R-CNN. Він дослідив та з'ясував, що найкраща точність для 75-25 перехресних перевірок та 90-10 перехресних перевірок становить 97,68\% та 98,75\% відповідно, і досягнута за допомогою архітектури згорткової нейронної мережі ZFNet.

Але, напроти, в роботі [7] теж використовується згорткова нейронна мережа, а саме архітектура AlexNet. B результаті розроблена модель зможе визначити, чи наданий сигнал електроенцефалограми показує нормальний чи аномальний стан, або стан хворого на Альцгеймера.

В роботі [8] пропонується новий метод обробки сканів головного мозку для діагностування Альцгеймеру. Спочатку для видалення розглядається база даних зображень небажаної області. Потім проміжний вихід надсилається для вилучення таких значних особливостей як, текстура, гістограма та масштабно-інваріантне перетворення 3 магнітно-резонансних зображень мозку. Для збільшення виявлення використовується техніка групової оптимізації сірого вовка продуктивність за допомогою дерева рішень, К-найближчого сусіда та класифікатора згорткової нейронної мережі.

В свою чергу, в роботі [9] було заявлено, що в останні роки дослідники успішно використовують штучні нейронні мережі для різних завдань класифікації зображень. Таким чином, надання МРТ в парі 3 нейронною мережею дасть лікарю впевненість та змогу перевірити свою відповідь щодо поставленого діагнозу і отримати об'єктивний звіт від навченої мережі. В своїй роботі автор використовує тривимірну модель нейронної мережі InceptionV3. Автор досяг 72\% точності на двовимірних даних.

Робота [10] теж пов'язана зі згортковими нейронними мережами, зокрема в ній пропонується тривимірна модель нейронної мережі. Автор роботи підкреслює ії головні переваги, що вона може допомогти в дослідженні і виявленні захворювання Альцгеймера шляхом відображення складної неоднорідності мозку, особливо в лімбічній системі і скроневій частці. 
Робота [11] демонструє аналіз мовного розладу хворого на Альцгеймер, він вважає, що як прямий і природний результат когнітивних порушень - мовний аспект хвороби привертає більшу увагу. Отримані результати показують, що запропонована таксономія мовних ознак, витягнутих із зразків мови, може бути використана для диференціації між пацієнтами 3 хворобою Альцгеймера та здоровою контрольною групою.

Робота [12] розглядає декілька інструментів машинного навчання: метод опорних векторів, дерева рішень та випадкові ліса для виявлення етапів розвитку хвороби в залежності від надання даних. Автор роботи зауважує, що останній підхід - це підхід глибокого навчання 3 використанням мультимодальних даних, який об'єднує зображення, генетичні дані і дані пацієнта 3 використанням глибоких моделей, а потім використовує об'єднані дані для більш ефективного виявлення стадії Альцгеймера.

В роботі [13] розглядається використання трансферного навчання на основі згорткової нейронної мережі для класифікації хвороби Альцгеймера. Автор випробували 13 різних зразків різних попередньо навчених моделей згорткової нейронної мережі, використовуючи доопрацьований підхід передачі навчання у двох різних областях на наборі даних ADNI. Зразок моделі DenseNet показав кращу продуктивність, досягнувши максимальної середньої точності 99,05\%.

Аналізуючи розглянуту літературу, можна побачити, що найбільш актуальним інструментом для виявлення хвороби, розпізнавання і класифікації стадій захворювання, в тому числі і хвороби Альцгеймера є згорткові нейронні мережі.

\section{Формулювання мети дослідження}

Мета даної роботи - розробити математичну модель згорткової нейронної мережі, що дозволить підвищити ступінь розпізнавання стадій захворювання Альцгеймера.

\section{Викладення основного матеріалу дослідження}

При розробці власної моделі нейронної мережі була обрана згорткова архітектура, тому що вона дає значно вищий процент розпізнавання [14], ніж інші архітектури нейронних мереж. Розроблена нейронна мережа має послідовну модель [15], це значить те, що шари нейронної мережі з'єднані від вхідного до вихідного шару послідовно, тобто, всі виходи вхідного шару з'єднуються зі входами наступного вихідного шару, кожний шар іде строго один за одним.

Модель була навчена на 4 класах хвороби, що відповідають 4 стадіям захворювання Альцгеймера, а саме: здоровий мозок, легкі когнітивні порушення, середній ступінь захворювання, тяжкий ступінь захворювання, запущена стадія хвороби. В структурі нейронної мережі це відображається наступним чином: останній, вихідний шар мережі має таку кількість нейронів, скільки було представлено навчених класів. Архітектуру розробленої згорткової мережі показано на рис. 1.

Перший шар нейронної мережі $\epsilon$ шар BatchNormalization(), що є вхідним, $є$ шаром нормалізації вхідних даних, тобто цей шар виконує нормалізацію вхідних зображень знімків магнітно-резонансної томографії пацієнтів. Він приймає в себе інформацію про вхідне зображення, а саме: ширину, висоту та кількість каналів.

Далі він з'єднується із першим згортковим шаром Conv2D(), який як зрозуміло з назви, виконує операцію згортки [16]. Цей згортковий шар містить в собі наступні параметри: перший - задає кількість фільтрів, в даному випадку тут вказано 32 фільтри, другий параметр - ядро згортки, що визначає ширину та висоту ядра згортки, в даному випадку воно задане розміром 3 на 3, третій параметр - «заповнення» встановлений із значенням «same» - він значить те, що відступи на зображенні будуть рівномірно заповненні нулями, четвертий параметр - це функція активації шару. Функцією активації даного шару $є$ лінійний випрямляч або RElu [17]. Працює вона наступним чином: всі негативні елементи перетворюються в нулі, а позитивні залишаються незмінними.

Далі іде другий згортковий шар Conv2D(), що має точно такі ж самі параметри. Наступним шаром іде перший шар підвибірки MaxPooling2D(), що зменшує розмір вхідних даних по заданій ширині і висоті, об'єднуючи двомірні дані. Він має параметри, що задані наступним чином: $(2,2)$ (ширина, висота).

Наступним шаром іде шар регуляризації Dropout() із значенням параметра 0.25 , тобто нейрони в цьому шарі будуть відключені із вірогідністю 25\%. Цей шар потрібен для того, щоб нейронна мережа не перенавчилась, що є дуже важливим зауваженням, в противному випадку нейронна мережа не зможе узагальнювати вступні дані та адекватно їх оцінювати.

Сьомий шар моделі містить шар нормалізації зображення, але вже без параметрів, далі ідуть два згорткових шари із наступними параметрами: 64 фільтри, ядро згортки 3 на 3, параметр «заповнення» із значенням «same», функція активації - RElu. Після них іде шар підвибірки розміром 2 на 2, далі іде шар регуляризації із значенням 0.25 .

Дванадцятий шар моделі знову складається з шару нормалізації даних без параметрів, далі знову ідуть два згорткових шари із наступними параметрами: 128 фільтрів, ядро згортки 3 на 3, параметр 
«заповнення» із значенням «same», функція активації - RElu, після них іде шар підвибірки розміром 2 на 2, наступний шар - шар регуляризації із значенням 0.25 .

Сімнадцятий шар моделі має наступні дані: це є шар Flatten(), що перетворює двовимірні дані до плоского виду, він потрібен для того, щоб повнозв'язний шар правильно обробляв вихідні дані від згорткового шару. Так як, згорткові шари будуть працювати із двовимірними зображеннями, необхідно привести їх до одного загального виміру ознак. Далі іде повнозв'язний шар Dense(), що має в собі 512 нейронів для виконання класифікації і активується за допомогою функції активації RElu.

Далі знову іде шар регуляризації Dropout() із вказаним параметром 0.25. Останній повнозв'язний шар моделі вказується із кількістю нейронів, що відповідають кількості класів - 4 нейрони. Функція активації в останньому шарі вказана softmax, тому що виконується багатокласова класифікація зображень: визначення, де немає захворювання, присутня початкова стадія хвороби Альцгеймера, середній ступінь важкості та запущена стадія хвороби.

Розроблена модель згорткової нейронної мережі для виявлення захворювання Альцгеймеру була перевірена на адекватність та протестована із такими параметрами: час навчання, загальна точність моделі, кількість епох навчання. Є чотири класи МРТ-сканів мозку, з якими модель нейронної мережі повинна співвідносити вхідні зображення головного мозку: здоровий мозок, легкі когнітивні порушення, середній ступінь захворювання Альцгеймера важкий ступінь Альцгеймера. Було проведено 50 досліджень із зміною кількості епох навчання нейронної мережі для виявлення оптимального значення кількості епох, за яким нейронна мережа буде більш ефективною. Навчання моделі відбувалось за допомогою сервісу Google Colaboratory. В таблиці 1 представлена частка результатів дослідження - дані перших 20 досліджень.

Перший стовпець означає номер проведеного експерименту, другий стовпець демонструє час навчання кожної моделі в секундах, третій стовпець показує загальну точність моделі, що була отримана в результаті тестування моделі, останній, четвертий стовпець означає кількість епох, які були вказані в якості параметру, який вказує нейронній мережі, яке число раз треба пройти по всьому навчальному наборі даних.

Таблиця 1

Результати тестування нейронної мережі

\begin{tabular}{|c|c|c|c|}
\hline $\begin{array}{c}\text { № } \\
\text { експерименту }\end{array}$ & $\begin{array}{c}\text { Час навчання } \\
\text { моделі, с }\end{array}$ & $\begin{array}{c}\text { Загальна точність } \\
\text { моделі, \% }\end{array}$ & $\begin{array}{c}\text { Кількість епох } \\
\text { навчання }\end{array}$ \\
\hline 1 & 1857 & 62 & 5 \\
\hline 2 & 1571,3 & 67,47 & 10 \\
\hline 3 & 1068,6 & 67,79 & 20 \\
\hline 4 & 761,7 & 70,05 & 25 \\
\hline 5 & 924,3 & 74,12 & 30 \\
\hline 6 & 1673 & 72,87 & 35 \\
\hline 7 & 1832 & 65,68 & 40 \\
\hline 8 & 2166,1 & 70,76 & 45 \\
\hline 9 & 3348 & 71,23 & 50 \\
\hline 10 & 2494,8 & 70,21 & 60 \\
\hline 11 & 2671,1 & 73,03 & 65 \\
\hline 12 & 2891 & 69,90 & 70 \\
\hline 13 & 3031 & 70,76 & 80 \\
\hline 14 & 3252,6 & 70,05 & 85 \\
\hline 15 & 3322,4 & 75,59 & 90 \\
\hline 16 & 3693,6 & 70,21 & 95 \\
\hline 17 & 4868,5 & 69,59 & 100 \\
\hline 18 & 3867,2 & 65,44 & 71,23 \\
\hline 19 & 4770,4 & 66,07 & \\
\hline 20 & 4342,4 & & 55 \\
\hline
\end{tabular}




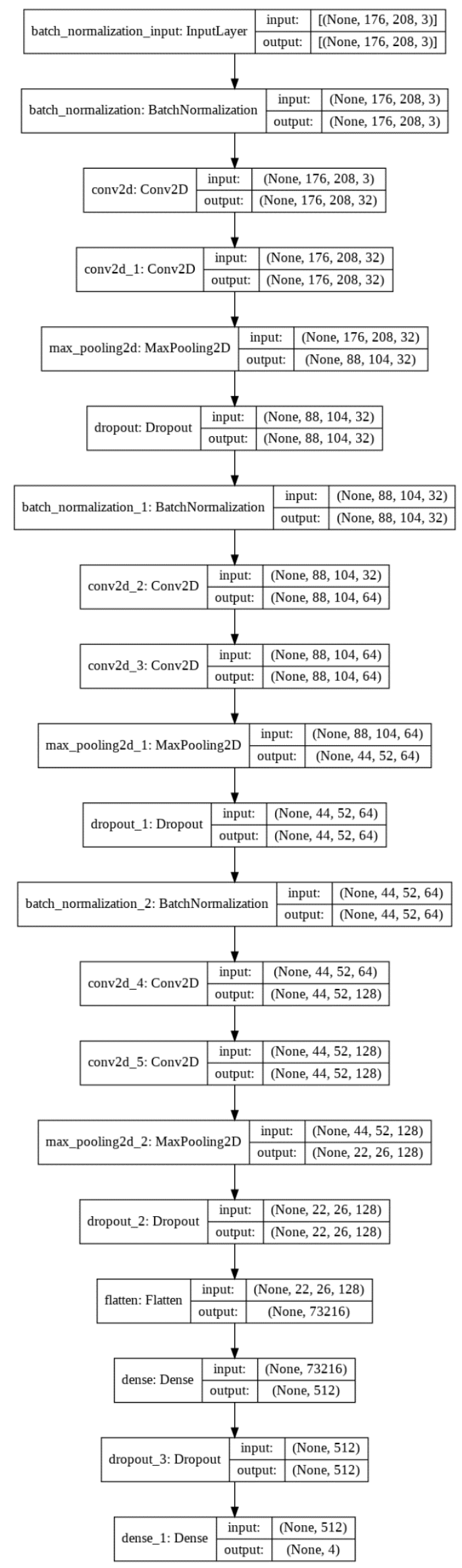

Рис. 1 - Архітектура нейронної мережі 
Аналізуючи отримані дані експериментів в таблиці, можна побачити, що найкращий результат був отриманий, коли модель мала параметр навчання в 75 епох, при цьому ії загальна точність розпізнавання стадій захворювання Альцгеймера складає 75,59\%. Так як основним критерієм відбору був обраний критерій загальної точності моделі, а саме, чим вище отримане значення після тестування моделі, тим краще вона справиться із задачею розпізнавання захворювання Альцгеймера. Таким чином, математична модель нейронної мережі, що має найвищий покажчик загальної точності була відібрана як основа для наступних експериментів щодо дослідження хвороби Альцгеймера, а саме: виявлення точності розпізнавання по кожній стадії захворювання Альцгеймера та витрачений час на розпізнавання.

\section{Висновки}

В ході виконання дослідження була розроблена математична модель згорткової нейронної мережі, що дозволяє визначати стадії захворювання Альцгеймера. В якості критеріїв оцінки математичної моделі було обрано загальну точність, що показала 75,59\% правильного розпізнавання хвороби.

На основі розробленої математичної моделі планується реалізація програмного забезпечення для використання непрофільними користувачами. Цей додаток можна використовувати при навчанні психіатрів при дослідженні хвороби Альцгеймера перед тим, коли майбутні фахівці будуть ставити діагнози в клініці реальним пацієнтам. Що в свою чергу дозволить підвищити рівень знань майбутніх лікарів в процесі навчання. Також майбутній додаток може допомогти в роботі неврологам: медичний працівник може перевірити свій поставлений діагноз пацієнту, спираючись на роботу додатка. Таким чином, досягається часткова автоматизація процесу постановки діагнозу та лікар отримує допомогу при виявленні захворювання, що в ритмі роботи лікарів є дуже актуальним оскільки частку контролю за виявленням патологій бере на себе спеціально навчена нейронна мережа.

\section{Список використаної літератури}

1. Knopman, David \& Amieva, Helene \& Petersen, Ronald \& Chételat, Gäel \& Holtzman, David \& Hyman, Bradley \& Nixon, Ralph \& Jones, David. (2021). Alzheimer disease. Nature Reviews Disease Primers. 7. 10.1038/s41572-021-00269-y.

2. Martinc, Matej \& Haider, Fasih \& Pollak, Senja \& Luz, Saturnino. (2021). Temporal Integration of Text Transcripts and Acoustic Features for Alzheimer's Diagnosis Based on Spontaneous Speech. Frontiers in Aging Neuroscience. 13. 10.3389/fnagi.2021.642647.

3. Chen, Xiaoxiao \& Li, Linghui \& Sharma, Ashutosh \& Dhiman, Gaurav \& Shanmuganthan, Vimal. (2021). The Application of Convolutional Neural Network Model in Diagnosis and Nursing of MR Imaging in Alzheimer's Disease. Interdisciplinary Sciences Computational Life Sciences. 3. 10.1007/s12539-021-00450-7.

4. Kumar, P \& Yung, Yang \& Huan, Tracy. (2017). Neural Network Based Decision Trees using Machine Learning for Alzheimer's Diagnosis. International Journal of Computer and Information Sciences. 4. 63-72.

5. Yiğit, Altuğ \& Isik, Zerrin. (2018). Application of artificial neural networks in dementia and alzheimer's diagnosis. 1-4. 10.1109/SIU.2018.8404447.

6. Janghel, Rekh. (2020). Deep-Learning-Based Classification and Diagnosis of Alzheimer's Disease. 10.4018/978-1-7998-0414-7.ch076.

7. Chellam, C \& Kumar, D \& S., Raja. (2021). An automated eeg based pathology and alzheimer detection using deep learning networks. Journal of Engineering and Technology Management. IX. 3143.

8. Shankar, Dr \& Lakshmanaprabu, S.K. \& Khanna, Ashish \& Tanwar, Sudeep \& Rodrigues, Joel \& Roy, Nihar. (2019). Alzheimer Detection Using Group Grey Wolf Optimization Based Features with Convolutional Classifier. Computers \& Electrical Engineering. 77. 10.1016/j.compeleceng.2019.06.001.

9. Poirier, James \& Tuttle, Michael. (2020). Artificial Neural Network to Detect Alzheimer's in MRI Scans.

10. Hogan, Ryan \& Christoforou, Christoforos. (2021). Alzheimer's Detection through 3D Convolutional Neural Networks.

11. Ammar, Randa \& Benayed, Yassine. (2020). Language-related features for early detection of Alzheimer Disease. Procedia Computer Science. 176. 763-770. 10.1016/j.procs.2020.09.071.

12. Patil, Adwait. (2021). A Comparative Study of Alzheimer Detection Techniques. International Journal for Research in Applied Science and Engineering Technology. 9. 2877-2883. 10.22214/ijraset.2021.37882.

13. Ashraf, Abida \& Naz, Saeeda \& Shirazi, Syed \& Razzak, Imran \& Parsad, Mukesh. (2021). Deep transfer learning for alzheimer neurological disorder detection. Multimedia Tools and Applications. 80. 10.1007/s11042-020-10331-8.

14. Salehi, Waleed \& Baglat, Preety \& Bhushan, Brij \& Gupta, Gaurav \& Upadhya, Ankita. (2020). A CNN Model: Earlier Diagnosis and Classification of Alzheimer Disease using MRI. 156 - 161. 10.1109/ICOSEC49089.2020.9215402. 
15. Aggarwal, Shilpi \& Bhatia, Madhulika \& Madaan, Rosy \& Pandey, Hari. (2021). Optimized Sequential model for Plant Recognition in Keras. IOP Conference Series: Materials Science and Engineering. 1022. 012118. 10.1088/1757-899X/1022/1/012118.

16. Ghiasi-Shirazi, Kamaledin. (2019). Generalizing the Convolution Operator in Convolutional Neural Networks. Neural Processing Letters. 10.1007/s11063-019-10043-7.

17. Płaczek, Stanisław \& Płaczek, Aleksander. (2018). Learning algorithm analysis for deep neural network with ReLu activation functions. ITM Web of Conferences. 19. 01009. 10.1051/itmconf/20181901009. 